\title{
Analisis Nilai Moral Dalam Film Animasi "The Boss Baby" Produksi Dreamworks Animation Bagi Siswa Sekolah Dasar
}

\author{
Dhanang Lukmantoro, Singgih Adhi Prasetyo, Husnul Hadi \\ 1,2,3 Pendidikan Guru Sekolah Dasar, Fakultas IImu Pendidikan, Universitas PGRI Semarang \\ Alamat email: dhanang.lukmantoro@gmail.com \\ Abstrak
}

Penelitian ini bertujuan untuk mengetahui apa saja nilai moral dalam Film Animasi "The Boss Baby" karya DreamWorks Animation bagi Siswa Sekolah Dasar. Jenis penelitian ini adalah penelitian kualitatif dengan subjek penelitian yaitu siswa kelas V SD Negeri 2 Tamanrejo. Data yang diperoleh menggunakan teknik simak catat, Kangket, wawancara, catatan lapangan, dan dokumentasi. Hasil penelitian yang telah dideskripsikan yaitu film animasi "The Boss Baby" mengandung nilai moral yang baik untuk anak usia sekolah dasar antara lain nilai kejujuran, keadilan, toleransi, bijaksana, disiplin diri, suka menolong, berbelas kasih, kerja sama, berani, dan demokratis. Namun untuk anak usia sekolah dasar hanya mampu menganalisis nilai kerja sama dan suka menolong dari film tersebut. Film ini dapat dijadikan sarana penanaman moral untuk anak dengan bimbingan guru ataupun orang tua..

Kata kunci: Nilai Moral, The Boss Baby, Sekolah Dasar

\section{Pendahuluan}

Kesuma, dkk (2013:2) mengungkapkan kondisi moral/akhlak generasi muda yang rusak /hancur. Hal ini ditandai dengan maraknya seks bebas di kalngan remaja (generasi muda), peredaran narkoba di kalangan remaja, tawuran pelajar, peredaran foto dan video porno pada kalangan pelajar, dan sebaginya.

Globalisasi layaknya pisau bermata dua yang mempunyai sisi positif dan negatif bergantung bagaimana menyikapinya. Namun globalisasi lebih banyak berdampak negatif seperti merambaknya konsumerisme, hendonisme, mengagung-agungkan ilmu teknologi, kemewahan yang tidak semestinya, foya-foya, pergaulan bebas, budaya kekerasan, pornografi, dan semacamnya. Pengaruh tersebut bukan hanya lewat dunia film, namun juga lewat media cetak dan televisi dengan satelitnya, serta sekarang yang sedang trend adalah internet. Intinya adalah nilai-nilai yang dibawa peradaban global, terutama peradaban Barat, memberi peradaban buruk bagi sikap dan perilaku masyarakat Indonesia (Winarno dan Herimanto 2011:90).

Tidak dapat dipungkiri bahwa anak-anak hidup dalam masa perkembangan yang pesat, terutama perkembangan fisik dan perkembangan mental. Untuk menunjang perkembangan fisik dan mental anak, sastra dapat dijadikan sebagai sarana penunjang, karena sastra dapat memberikan nilai-nilai tinggi bagi proses perkembangan bahasa, kognitif, personalitas, dan sosial anak (Ampera 2010:09).

Menurut Nurgiantoro dalam (Albarikah 2017:4) Film yang merupakan refleksi dari kehidupan sosial masyarakat ini juga mengandung penerapan moral dalam sikap dan tingkah laku para tokoh sesuai dengan pandangannya tentang moral. Melalui cerita yang ditampilkan dalam film serta sikap dan tingkah laku tokoh dalam film para penonton film diharapkan dapat mengambil pesan-pesan moral yang disampaikan dalam film tersebut.

Salah satu film yang digemari oleh anak-anak adalah film animasi, karena dalam jenis film ini dikemas dengan suasana humor dan lucu yang menarik. Salah satu contoh film animasi adalah "The Boss Baby" yang di produksi oleh studio film DreamWorks Animation. Film ini merupakan fillm animasi yang bergenre komedi. Karakter dari film "The Boss Baby" yaitu mengambil tentang dunia anak yang menyakup seluruh kehidupan anak-anak. Film ini mengisahkan dari latar belakang kehidupan anak di dalam keluarga di mana terdapat kakak beradik yang bermusuhan namun mampubekerja sama dengan baik dalam menyelesaikan suatu masalah. Hal tersebut sesuai dengan kehidpan anak Sekolah Dasar yang tentunya 
mempunyai sebuah saudara agar menjadi sebuah sarana kerukunan antar saudara dalam keluarga

Film yang diproduksi oleh DreamWorks Animation ini juga menggambarkan kehidupan anak yang sudah bertindak kedewasaan, di mana seorang anak yaitu Boss Baby telah menggunakan alat elektronik berupa ponsel sebagai alat komunukasi. Hal tersebut tidak jauh berbeda dengan kehidupan anak Sekolah Dasar zaman sekarang yang sebagaian besar telah menggunakan ponsel sebagai alat komunikasi ataupun sekedar sebagai permainan. Namum yang namanya ponsel tentu adanya sisi positif dan negatifnya mengingat bahwa banyak situs dewasaa yang dengan sangat mudah diakses menggunkan ponsel modren. Namun hal tersebut dapat kita antisipasi bergantung bagaimana para orang tua selalu mengawasi anak mereka dalam menggunakan ponsel tersebut agar tidak merusak moral yang baik oleh kemajuan teknologi ini. Oleh sebab itu penulis tertarik untuk menganalisis nilai moral dalam film animasi "the Boss Baby", sehingga penulis memilih judul "Analisis Nilai Moral dalam Film Animasi "The Boss Baby" produksi DreamWorks Animation bagi Siswa Sekolah Dasar".

Dalam KBBI Moral didefinisikan sebagai: (1) (ajaran tentang) baik buruk yang diterima umun mengenai perbuatan, sikap, kewajiban, dan sebagainya; (2) kondisi mental yang membuat orang tetap berani, bersemangat, bergairah, berdisiplin, dan sebagainya; (3) ajaran kesusilaan yang dapat ditarik dari suatu cerita (Kesuma 2012:22). Menurut Winarno dan Herimanto (2011:129) istilah moral dapat dipersamakan dengan istilah etika, etik, akhlak, kesusilaan, dan budi perkerti. Dalam hubungannya dengan nilai, moral adalah bagian dari nilai, yaitu nilai moral. Jadi nilai moral adalah baik buruknya sesuatu yang mempunyai ukuran

Menurut Lickona (2013:64-65) sikap hormat dan tanggung jawab adalah dua nilai moral dasar yang harus diajarkan di sekolah. Adapun contoh dari nilai moral yang lain adalah (1) kejujuran, (2) keadilan, (3) toleransi, (4) bijaksana, (5) disiplin diri, (6) suka menolong, (7) berbelas kasih, (8) kerja sama, (9) berani, dan (10) demokratis. Nilai-nilai tersebut terbentuk dari dari sikap hormat dan tanggun jawab atau pelengkap tindakan yang dilakukan dengan sikap hormat dan tanggung jawab.

Tahapan perkembangan moral anak menurut Piaget dalam (Ardini 2012:52) (a) Moralitas heteronom (usia 4-7 tahun), (b) Transisi (7-10 tahun), (c) Moralitas Otonom (10 tahun keatas). Anak usia 7-10 tahun berada pada tahap transisi, yaitu tahap peralihan dari pemikiran bahwa aturan-aturan tentang baik-buruk dibuat mutlak oleh orang dewasa dan Tuhan sehingga tidak seorangpun bisa merubah menjadi pemikiran bahwa aturan-aturan tersebut hanya alat yang dibuat secara kooperatif dengan orang dewasa. Maka pada usia ini penanaman moral yang baik akan berdampak sampai mereka tumbuh remaja dewasa.

Sastra menampilkan cerita yang menarik, mengajak pembaca untuk memanjakan fantasi. Itegaskan juga bahwa sastra bertujuan untuk memberikan hiburan, tujuan menyenangkan dan memuaskan pembaca, tidak peduli pembaca dewasa ataupun anak-anak, adalah hal yang esensial dalam sastra.

Huck, dkk dalam (Nurgiyantoro 2010:6) berpendapat bahwa perlu adanya perhatian terhadap perbedaan buku yang dimaksudkan sebagai bacaan anak dan dewasa. Bagaimapun juga isi kandungan sastra anak dibatasi oleh pengalaman dan dijangkau dan dipahami oleh anak, pengalaman dan pengetahuan anak yang sesuai dengan dunia anak sesuai dengan perkembangan emosi dan kejiwaannya. Menurut Huck, ddk isi kandungan yang terbatas sesuai dengan jangkauan emosional dan psikologi anak itulah yang antara lain merupakan karakteristik sastra anak. Sastra anak dapat berkisah tetang apa saja, bahkan yang menurut ukuran dewasa tidak masuk akal. Misalnya, kisah binatang yang dapat berbicara, bertingkah laku, berpikir dan berperasaan layaknya manusia

Teori strukturalisme bertujuan untuk memaparkan secermat mungkin mengenai fungsi dan keterkaitan antar berbagai unsur yang secara bersama menghasilkan sebuah kemenyeluruhan. Dalam sebuah karya sastra terdapat dua unsur, yaitu unsur intrinsik dan unsur ekstrinsik (Fadli dan Rahma 2016:6).

Menurut Nurgiyantoro dalam (Fadli dan Rahma 2016:6) unsur intrinsik adalah unsurunsur yang membangun karya sastra itu sendiri, yang menyebabkan karya sastra hadir sebagai karya sastra, yang secara faktual akan dijumpai jika orang yang membacanya. Unsur intrinsik tersebut terdiri atas tokoh, sifat atau watak, alur, latar, tema, amanat. Sedangkan Unsur ekstrinsik merupakan unsur yang berada di luar karya sastra, yang menghubungkan karya sastra dengan sosial masyarakatnya, misalnya faktor kebudayaan, faktor sosial ekonomi, faktor sosial politik, keagamaan, dan tata nilai yang dianut masyarakat 
Kata animasi berasal dari bahasa Latin, anima yang berartin "hidup" atau animare yang berarti "meniupkan hidup ke dalam". Kemudian istilah tersebut dialihbahasakan ke dalam bahasa Ingrris animate yang berarti memberi hidup (to give life to., atau animation yang berarti ilusi dalam gerakan. Dalam KBBI (2002:53) kata animasi diartikan lebih teknis yaitu acara televisi yang berbentuk rangkaian lukisan atau gambar yang digerakan secara mekanik elektronis sehingga tampak di layar menjadi bergerak (Sugihartono 2010:9).

(Sugihartono 2010:51) Animasi merupakan suatu teknik visualisasi yang banyak sekali dipakai di dalam dunia perfilman, baik sebagai kesatuan yang utuh, bagian dari live action, maupun bersatu dalam live action. Film "The Boss Baby" merupakan sebuah animasi yang utuh. Dapat dikatakan animasi utuh karena semua yang ada di dalam film tersebut dari tokoh, adegan, tempat, ornamen pembentuk semuanya dalah teknik visualisasi animasi

"The Boss Baby" adalah film 3D animasi komputer Amerika Serikat bergenre komedi yang diankat dari buku berjudul sama terbitan 2010 yang ditulis dan diilustrasikan oleh Marla Frazee. Film ini diprosuksi oleh DreamWorks Animaton, disutradarai oleh Tom Mc Grath berdasarkan skenario hasil tulisan Michel Mc Cullers. "The Boss Baby" disuarakan oleh beberapa bintang antara lain Alec Baldwin, Miles Bakshi Steve Buscemi, Jimmy Kimmel dan Lisa Kudrow bersama Tobey Maguire sebagai narator. Tokoh dalam film ini antara lain Timothy Templeton sebagai anak tunggal dari keluarga, Baby Boss yaitu bayi yang datang di keluarga, Francis E. Francis yaitu CEO Pupy Co, Mr. Templeton dan Mrs. Templeton sebagai pasangan suami istri dan orang tua dari Timothy Templeton (id.wikipedia.org).

\section{Metode}

Jenis penelitian yang digunakan dalam penelitian ini adalah penelitian deskriptif kualitatif. Penelitian deskriptif merupakan penelitian yang diperoleh berupa kata-kata, gambar dari film animasi "The Boss Baby" dan bukan data berbentuk angka-angka. Prosedur pengumpulan data primer yang digunakan dengan menggunakan teknik simak catat, kuisioner, wawancara, observasi (catatan lapangan), dan dokumentasi

Simak catat dilakukan karena peneliti terlibat langsung di dalamnya, maka peneliti mengamati dan menyimak sumber data yang berupa film animasi "The Boss Baby" kemudian mencatat hasilnya yaitu menyimak film animasi di dalamnya menggunakan tabel nilai moral. Kuisioner/angket yaitu pengambilan data dengan cara memberi seperangkat pertanyaan atau pernyataan tertulis kepada responden untuk dijawab. Angket yang digunakan dalam penelitian ini berisi tentang hal-hal yang menyangkut tentang nilai moral. Dalam hal ini peneliti memberikan angket kepada siswa sebagai subjek penelitian dan responden

Wawancara yang dilakukan wawancara terstruktur, di mana peneliti atau pengumpul data telah mengetahui dengan pasti tentang informasi apa yang akan diperoleh. Wawancara dilakukan dengan siswa, guru kelas, kepala sekolah, dan orang tua siswa.

Observasi (Catatan Lapangan) adalah observasi tidak tertruktur yang tidak dipersiapkan secara sistematis. Dalam melakukan pengamatan peneliti tidak menggunakan instrumen yang baku. Oleh karena itu peneliti dapat melakukan pengamatan bebas, mencatat apa yang membuat peneliti tertarik dalam proses penelitian.

Dokumentasi merupakan catatan peristiwa yang sudah berlalu. Dokumen bisa berbentuk tulisan, gambar, atau karya-karya monumental dari seseorang. Dokumen juga ada yang berbentuk karya seni yang dapat berupa gambar, patung, film, dan lain-lain. Dalam penelitian ini akan dilakukan pengamatan terhadap film animasi "The Boss Baby" sebagai dokumen karya seni.

\section{Hasil dan Pembahasan}

Film animasi yang menjadi data penelitian adalah film animasi "The Boss Baby" yang diproduksi oleh DreamWorks Animation. Film ini memiliki durasi selama 01 jam 37 menit 30 detik. Di putar perdana di Indonesia pada tanggal 5 April 2017 di bioskop seluruh Indonesia. Latar belakang dari film ini yaitu menceritakan tentang kehidupan anak-anak secara nyata, dari kehidupan keluarga sampai kehidupan tempat bermainnya. Selain menceritakan kehidupan anak film ini juga berkisah tetang kehidupan orang dewasa secara tersirat di masa modern ini. Dari film ini Boss Baby tidaka hanya sebagai seorang bocah bayi biasa. Boss Baby mempunyai sebuah pekerjaan terikat dengan Baby Corp di mana dia sendiri dituntut menyelesaikan 
sebuah misi agar jabatan dia naik tanpa mengingat sebuah keluarga. Hal tersebut mejadi sebuah pelajaran bagi orang dewasa bahwa jabatan tidak selalu harus dikejar. Kita mendapat jabatan yang tinggi tentu dengan dorongan dan doa dari orang terdekat contohnya keluarga.

Film animasi "The Boss Baby" ini memiliki beberapa tokoh karakter yaitu Tim Templeton, Boss Baby, Ted dan Janice Templeton, Francis E. Francis, Eugine, Jimbo, Staci, dan 3 Bayi Kembar. Latar tempat dari cerita ini adalah kamar tidur, kamar mandi, ruang makan, halaman rumah, Pupy Co, Bandara, Pesawat, dan Las Vegas Convention. Terjadinya cerita ini berada dalam waktu pagi , siang, dan sore hari.

Dari hasil analisis yang telah dilakukan film animasi "The Boss Baby" memiliki 10 nilai moral. Nilai moral yang terkandung di dalamnya adalah nilai kejujuran, keadilan, toleransi, bijaksana, disiplin diri, suka menoloing, berbelas kasih, kerja sama, berani, dan demokrasi. Berikut tabel analisis nilai moral dalam film animasi "The Boss Baby"

Tabel 1. Nilai Moral Film "The Boss Baby"

\begin{tabular}{|c|c|}
\hline Nilai Moral & Deskripsi \\
\hline Kejujuran & $\begin{array}{l}\text { Tokoh Tim encoba jujur kepada orang tua bahwa Boss Baby bisa biacara } \\
\text { layaknya orang dewasa } \\
\text { Tim tidak bersedia disuap dengan uang } \\
\text { Boss Baby jujur kepada Tim atas siapa identtias asli dirinya }\end{array}$ \\
\hline Keadilan & $\begin{array}{l}\text { Boss Baby memilih untuk menyelamatkan orang tua Tim dan } \\
\text { perusahaannya demi keuntungan bersama } \\
\text { Memberi hadiah kepada bayi lain sesuai dengan kebutuhan/keinginan } \\
\text { masing-masing }\end{array}$ \\
\hline Toleransi & $\begin{array}{l}\text { Tim mengajak Boss Baby untuk berbagi kasih sayang dari porang tuanya } \\
\text { Boss Baby mengajak Tim untuk menyingkirkan perbedaan }\end{array}$ \\
\hline Bijaksana & $\begin{array}{l}\text { Salah satu bayi meminta untuk memasang sabuk pengaman } \\
\text { Boss Baby menasehati akan jangan takut gagal }\end{array}$ \\
\hline Disiplin & $\begin{array}{l}\text { Boss Baby tidak suka membuang waktu yang tidak penting } \\
\text { Tim Tetap fokus pada tujuan awal yaitu menhentikan kejahatan Francis E. } \\
\text { Francis } \\
\text { Tim tetap memaikai helm saat berkendara agar aman walau dalam kondisi } \\
\text { terburu-buru }\end{array}$ \\
\hline Suka & Tim menolong orang tua dari ikan hiu \\
\hline Menolong & Tim akan menolong/membantu Boss Baby untuk misinya \\
\hline Belas Kasih & $\begin{array}{l}\text { Boss Baby merasakan kesedihan yang dialami Tim } \\
\text { Tim merasakan kehidupan Boss Baby tanpa adanya kasih sayang orang } \\
\text { tua }\end{array}$ \\
\hline Kerja Sama & $\begin{array}{l}\text { Tim dan Boss Baby bekerja sama untuk mengalahkan Francis E. Francis } \\
\text { Kerjsa sama antara bayi dalam membantu Tim dan Boss Baby } \\
\text { Bekerja sama untuk melawan Francis E. Francis }\end{array}$ \\
\hline Berani & $\begin{array}{l}\text { Tim merasakan seram namun tetap melanjutkan tujuannya untuk } \\
\text { mengambil berkas rahasi } \\
\text { Berani melawan pengasuh jahat untuk mereka dapat bebas (Eugine) }\end{array}$ \\
\hline Demokratis & $\begin{array}{l}\text { Kerja sama Tim dan Boss Baby untuk tujuan bersama } \\
\text { Menerima dan menyampingkan perbedaan untuk tujuan bersama }\end{array}$ \\
\hline
\end{tabular}

Dari hasil analisis data siswa dan catatan lapangan yang telah dipadukan bahwa siswa menonton film tersebut dengan kondisi tertib dan tetap fokus. Maka dengan kondisi demikian, tentunya siswa menyimak film tersebut dengan seksama dan konsentrasi yang dapat dikatakan tinggi. Dari hasil angket yang telah di analisis, sebagian besar siswa menemukan sepuluh nilai moral dari film animasi "The Boss Baby" tersebut. Namun kondisi lain berbeda setelah peneliti melakukan wawancara terhadap semua siswa. Dari wawancara yang telah dilakukan siswa tersebut bahwa mereka hanya menemukan nilai moral kerja sama, berani dan suka menolong. Dari kondisi ini peneliti menemukan hal baru bahwa film animasi "The Boss Baby" merupakan film berat bagi siswa sekolah dasar dalam hal menganalisis nilai-nilai moral yang terkadung di dalamnya. 
Dari hasil wawancara dari ke tiga sumber, yaitu guru kelas, kepala sekolah, dan orang tua siswa dapat disimpulkan bahwa film animasi "The Boss Baby" memiliki nilai moral yang baik dan cocok di ditonton untuk anak usia SD. Namun dalam hal menonton film animasi tersebut, bimbingan dan pengawasan orang tua tetap harus diperhatikan agar anak tidak salah menangkap isi pembelajaran yang terdapat dari film tersebut. film animasi ini juga dapat dijadikan sebagai media pengantar moral dalam proses belajar mengajar di kelas, dengan penyampaian yang tepat dari guru yang bersangkutan agar kandungan nilai dari film ini dapat tersampiakan bagi siswa sekolah dasar.

\section{Kesimpulan}

Berdasdarkan dari hasil penelitian dan pembahasan yang telah diuraikan, dapat disimpulkan bahwa terdapat nilai moral dalam film animasi "The Boss Baby" produksi DreamWorks Animation. Nilai moral yang terkandung di dalam film animasi "The Boss Baby" ini adalah nilai kejujuran, keadilan, toleransi, bijaksana, disiplin, suka menolong, berbelas kasih, kerja sama, berani, dan demokratis.

Film animasi "The Boss Baby" masih terlalu berat jika dianalisis nilai moralnya oleh anak usia Sekolah Dasar karena siswa hanya mampu menganalisis nilai kerja sama, berani, dan suka menolong. Film animasi "The Boss Baby" ini tetap masih dapat ditonton oleh anak usia Sekolah Dasar dan dapat dijadikan sarana penanaman moral dengan bimbingan orang tua serta guru agarl nilai positif yang ada di dalam film tersebut mampu d oleh anak dengan baik.

\section{Daftar Pustaka}

Ampera, Taufik.2010. Pengajaran Sastra. Bandung: Widya Padjajaran.

Fadli dan Rahma. 2016. Analisis Struktur dan Nilai-Nilai Moral yan terkandung dalam Cerpen Made Todoke Karya Yoshida Genjiro. Naskah Publikasi. Semarang: UNDIP. diunduh 13 Desember 2018.

Ghony, Djunaidi \& Fauzan Almanshur. 2017. Metodologi Penelitian Kualitatif. Yogyakarta: ArRuzz Media.

IMDB. 2017. The Boss Baby. https://www.imdb.com/title/tt3874544/releaseinfo. diunduh 28 November 2018.

Kesuma, Dharma, dkk. 2013. Pendidikan Karakter. Bandung: Rosda.

Lickona, Thomas. 2013. Pendidikan Karakter Panduan Lengkap Mendidik Siswa Menjadi pintar dan Baik. Bandung: Nusa Media.

Maghfiroh. 2015. Analisis Pesan Moral dalam Film Animasi "Pada Zaman Dahulu" Full Movie Karya Aliya Nazlan dkk. Skripsi. Semarang: Fakultas IImu Pendidikan Universitas PGRI Semarang (tidak diterbitkan).

Milawati, Teti. 2011. Peningkatan Kemampuan Anak Memahami Drama dan Menulis Teks Drama Melalui Model Pembelajaran Somatis Auditori Visual Intelektual (SAVI). Naskah Publikasi. Jakarta: UPI. http://jurnal.upi.edu/file/8-Teti_Milawati-edit.pdf. diunduh 17 Desember 2018.

Moleong, Lexy J. 2013. Metodologi Penelitian Kualitatif. Bandung: PT Remaja Rosdakarya.

Nurgiyantoro, Burhan. 2010. Sastra Anak. Yogyakarta: Gadjah Mada University Press..

Keppres. 2014. Peraturan Pemerintah No. 18Tahun 2014 tentang Lembaga Sensor Film. Jakarta.

Sugihartono, Ranang Agung, dkk. 2010. Animasi Kartun. Jakarta: PT Indeks. 
Jurnal Filsafat Indonesia, Vol 1 No 32018

ISSN: E-ISSN 2620-7982, P-ISSN: 2620-7990

Sugiyono. 2017. Metode Penelitian Pendidikan. Bandung: Alfabeta

Winarno dan Herimanto. 2011. Ilmu Sosial \& Budaya Dasar. Jakarta: PT Bumi Aksara. 